\title{
Localized Eruptive Blue Nevi after Herpes Zoster
}

\author{
Fany Colson $^{a} \quad$ Jorge E. Arrese ${ }^{b} \quad$ Arjen F. Nikkels $^{a}$ \\ ${ }^{a}$ Department of Dermatology, CHU du Sart Tilman, University of Liège, Liège, Belgium; \\ ${ }^{b}$ Department of Dermatopathology, CHU du Sart Tilman, University of Liège, \\ Liège, Belgium
}

\section{Keywords}

Eruptive melanocytic nevi · Blue nevus · Herpes zoster · Zosteriform distribution · Melanocytic nevus

\begin{abstract}
A 52-year-old White man presented with a dozen small, well-restricted, punctiform, asymptomatic, blue-gray macules on the left shoulder. A few months earlier, he had been treated with oral acyclovir for herpes zoster ( $\mathrm{HZ}$ ) affecting the left $\mathrm{C} 7-\mathrm{C} 8$ dermatomes. All the blue macules appeared over a short period of time and then remained stable. The patient had not experienced any previous trauma or had tattooing in this anatomical region. The clinical diagnosis suggested blue nevi. Dermatoscopy revealed small, well-limited, dark-blue, compact, homogeneous areas evoking dermal blue nevi. An excisional biopsy was performed and the histological examination confirmed a blue nevus. As far as we are aware of, this is the first report of eruptive blue nevi following $\mathrm{HZ}$, and it should be included in the differential diagnosis of zosteriform dermatoses responding to an isotopic pathway. In addition, a brief review concerning eruptive nevi is presented.

(C) 2016 The Author(s)

Published by S. Karger AG, Basel
\end{abstract}

\section{Introduction}

Eruptive melanocytic nevi (EMN) are defined as the appearance of numerous pigmented macules and/or papules on the skin in a short period of time with a histological aspect of

KARGER 
melanocytic nevus. These nevi can be of the junctional, dermal, compound, atypical, blue, or Spitz nevus subtypes [1]. Among EMN, eruptive blue nevi (EBN) have been reported following traumatic skin events [2]. EBN can occur at various anatomical locations [3]. However, as far as we know, the occurrence of EBN following a cutaneous infection with the Varicella zoster virus has never been previously described.

\section{Case Report}

A 52-year-old White man presented with a dozen small, well-restricted, blue-gray macules on the left shoulder (fig. 1). The lesions were asymptomatic. They all had appeared over a few days and subsequently remained unchanged. At precisely this site (left C7-C8 dermatomes), he had been treated 2 months earlier for herpes zoster (HZ) with oral acyclovir (800 $\mathrm{mg} \times 5 /$ day, for 7 days). He did not suffer from persisting postherpetic neuralgia. The patient did not report any previous trauma or tattoo in this area. The patient was otherwise healthy and had never presented any other dermatoses in the past. He did not take any drugs and had no particular medical, allergological, or surgical past history.

Blue nevi were suspected on clinical examination. Dermatoscopy revealed blue, homogeneous, symmetrical, structureless, well-limited, small areas evoking blue nevi. An excisional biopsy was performed under local anesthesia. A dermatopathological examination revealed small bundles of heavily pigmented, spindle-shaped melanocytes and melanophages in the middle dermis. This was highly suggestive of a common blue nevus of the cellular type (fig. 2).

A final diagnosis of EBN on a skin site previously involved by $\mathrm{HZ}$ was made. As the lesions were completely asymptomatic and did not bother the patient, no particular treatment was performed. An annual follow-up was recommended.

\section{Discussion}

EMN can occur following a wide array of cutaneous events (table 1) [1-13]. EMN occurring after healed bullous dermatoses tend to be located at the sites of previously involved areas. In contrast, EMN related to the use of immunosuppressive drugs can be diffuse or localized, e.g. palmoplantar. Widespread EMN are more common in the event of an immunosuppression and during endocrinopathies [6]. The occurrence of EMN is sometimes partially reversible if the cause is interrupted $[2,12]$.

EMN exhibit several typical clinical and dermatoscopic features [8] probably related to their new appearance and recent growth. In fact, in young renal allograft recipients and in patients using immunosuppressive drugs, dermatoscopic examination reveals a peripheral rim of brown globules $[1,2]$. The dermatoscopic aspect of palmoplantar EMN is, however, not specific: a fibrillar pattern on weight-bearing areas, lattice-like pigmentation on the arch of the soles, and parallel furrow patterns elsewhere, sometimes with a few small globules [3]. Proliferating melanocytes could be derived from subclinical melanocytic nests or could have an adnexal origin based on histological features [1]. This hypothesis may explain the frequent palmoplantar distribution.

Several hypotheses have been advanced to explain the phenomenon of EMN. Drugs or stress conditions could trigger their proliferation through growth factor production. A deregulation of $\mathrm{T}$ lymphocyte activity may lead to an overexpression of melanoma growth- 
stimulating activity (MGSA) gene and/or melanocyte-stimulating hormone (MSH) gene products in stress contexts (chemotherapy, leukemia, etc.) [6]. Skin injuries and bullous diseases could also play a part in the pathogenesis. Indeed, cytokines and growth factors are involved in epidermal regeneration [1]. For instance, basal keratinocytes and fibroblasts produce basic fibroblast growth factor during the healing process, which has a mitogen effect on melanocytes [14]. Other mechanisms are also suggested to explain the association between EMN and bullous diseases: nevocyte dispersion in the blister's cavity with secondary replication on the base of the bullous lesion, the Koebner phenomenon, etc. [2].

Escape from BRAF- and NRAS-induced senescence corresponds to the second main hypothesis. It is supported by vemurafenib (BRAF inhibitor)-triggered EMN [10]. After an initial transient, proliferative phase induced by oncogenic mutation as BRAF V600E, EMN enter a growth arrest state. This is associated with mosaic expression of the p16INK4 tumor suppressor and an intense activity of senescence-induced acidic $\beta$-galactosidase, both senescence markers. The heterogeneous induction of p16INK4 in growth-arrested melanocytes suggests a role of other factors in protection against oncogen-driven proliferation. Any disturbance in this process could lead to senescence escape and melanocyte replication. Some authors suggest that effects of synthetic $\alpha$-MSH and ACTH could also promote senescence escape. These two (both with $\alpha$-MSH-like activity) bind to the melanocortin receptors MCR1 and MCR5, leading to overexpression of enzymes involved in melanin synthesis and melanocyte proliferation [1].

Concerning EBN in particular, different locations are mentioned in the literature, including the scalp, glans penis, legs, and face. They have been described following traumatisms in the form of sunburn in a child and after an accidental head injury. They also have been associated with an Ota nevus and with cutis marmorata telangiectatica congenita. Sometimes multiple causes are invoked, such as Ota nevus with possible triggering by sunbed use and exposure to oral contraceptives [4].

The site of previous HZ is prone to the development of a wide array of dermatoses, mostly granulomatous reactions, inflammatory skin diseases such as lichen sclerosus, lichen planus, and morphea, as well as benign and malignant tumoral lesions including eruptive keratoacanthoma, lymphoma, and melanoma [15]. In terms of pathogenesis, the development of EBN on the site of a previously healed $\mathrm{HZ}$ eruption probably also follows an isotopic pathway. HZ-induced lesions of dermal sensory nerves could lead to disturbances of neuropeptide functions with local neuroimmune deregulation or growth factor activity acquisition [15].

\section{Conclusion}

To our knowledge, this is the first case of EBN after HZ. It is important to consider it in a differential diagnosis of zosteriform dermatoses from the isotopic pathway.

\section{Statement of Ethics}

No ethics approval was required. 


\section{Disclosure Statement}

The authors declare no competing interests. There was no funding for this work.

\section{References}

1 Salopek TG, Mahmood MN: Eruptive melanocytic nevi induced by interferon for nodal metastatic melanoma: case report and review of the literature. J Cutan Med Surg 2013;17:410-413.

-2 Arnold SJ, Bowling J: Eruptive acral naevi following chemotherapy for acute lymphoblastic leukaemia follow typical acral dermoscopic patterns. Australas J Dermatol 2013;54:126-128.

-3 Mazaud C, Chevallier B, Sigal M-L, Mahé E: Childhood eruptive nevi: a case report (in French). Arch Pediatr 2015;22:409-413.

4 Kesty K, Zargari O: Eruptive blue nevi. Indian J Dermatol Venereol Leprol 2015;81:198-201.

5 Lee JH, Kang JH, Cho BK, Park HJ: Dysplastic nevus with eruptive melanocytic lesions that developed during nilotinib therapy for chronic myeloid leukemia. Ann Dermatol 2015;27:782-784.

-6 Koseoglu G, Akay BN, Kucuksahin O, Erdem C: Dermoscopic changes in melanocytic nevi in patients receiving immunosuppressive and biologic treatments: results of a prospective case-control study. J Am Acad Dermatol 2015;73:623-629.

-7 Bogenrieder T, Weitzel C, Schölmerich J, Landthaler M, Stolz W: Eruptive multiple lentigo-maligna-like lesions in a patient undergoing chemotherapy with an oral 5-fluorouracil prodrug for metastasizing colorectal carcinoma: a lesson for pathogenesis of malignant melanoma? Dermatology 2002;205:174175.

8 Anforth RM, Carlos GR, Scolyer RA, Chou S, Fernandez-Peñas P: Eruptive naevi in a patient treated with LGX818 for BRAF mutant metastatic melanoma. Melanoma Res 2015;25:91-94.

-9 Jiménez-Gallo D, Albarrán-Planelles C, Linares-Barrios M, Martínez-Rodríguez A, Báez-Perea JM: Eruptive melanocytic nevi in a patient undergoing treatment with sunitinib. JAMA Dermatol 2013;149:624-626.

10 Sibaud V, Munsch C, Lamant L: Eruptive nevi and hair depigmentation related to regorafenib. Eur J Dermatol 2015;25:85-86.

-11 Cruz A, Sánchez JL: Acral PUVA-induced pigmented macules. Bol Asoc Med PR 1990;82:460-462.

12 Tofahrn J, Hundeiker M: Nevus eruption following thyroidin with spontaneous involution (in German). Z Hautkr 1976;51:617-620.

13 Kim DH, Lee JS, Koo DW, Jung KE: Eruptive melanocytic nevi with satellite lesions following insulin treatment in a girl with type 1 diabetes mellitus. J Dermatol 2015;42:547-548.

14 Chodorowska G, Tomczyk M, Glowacka A: Basic-fibroblast growth factor (b-FGF) - its biological role in physiologic and pathologic conditions. Ann Univ Mariae Curie Sklodowska Med 2004;59:286-291.

$\checkmark 15$ El Hayderi L, Libon F, Nikkels-Tassoudji N, Ruebben A, Dezfoulian B, Nikkels AF: Zosteriform dermatoses - a review. Glob Dermatol 2015;2:163-173. 


\section{Case Reports in

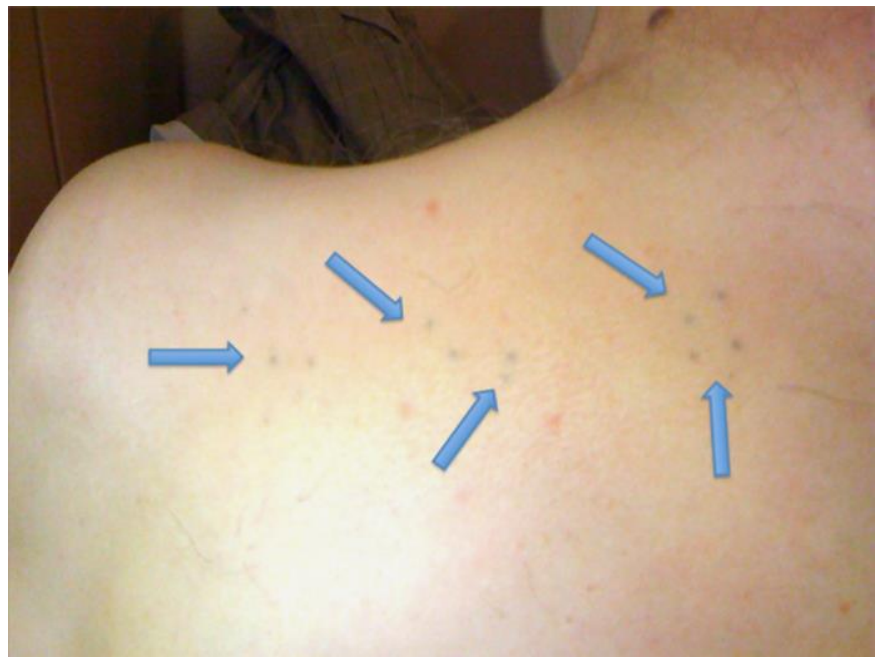

Fig. 1. EBN (blue arrows) on the left shoulder in a zosteriform distribution.

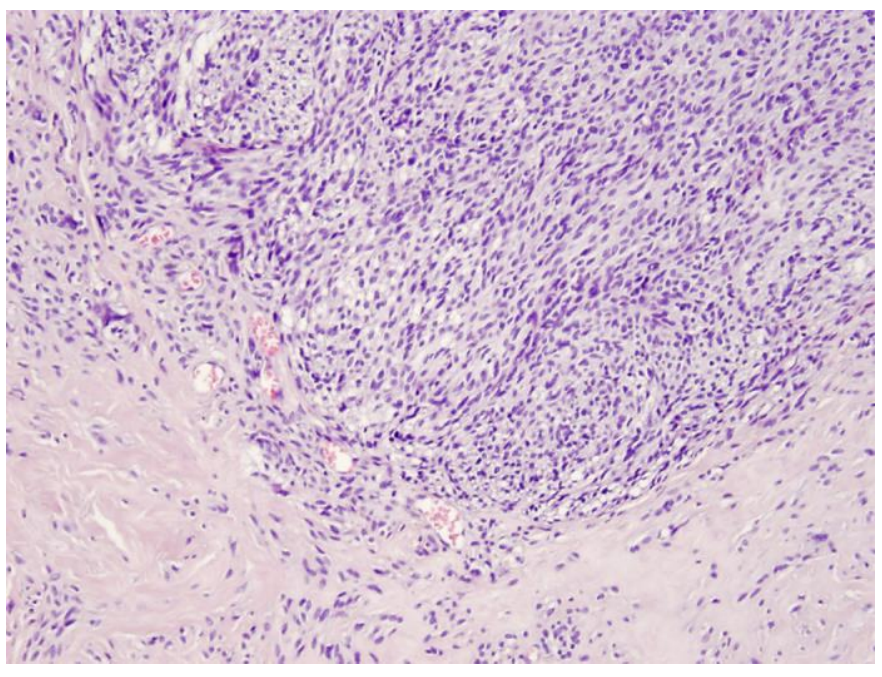

Fig. 2. Histology revealing a blue nevus. 
Table 1. Summary of causes of EMN

\begin{tabular}{|c|c|}
\hline Immunosuppression & 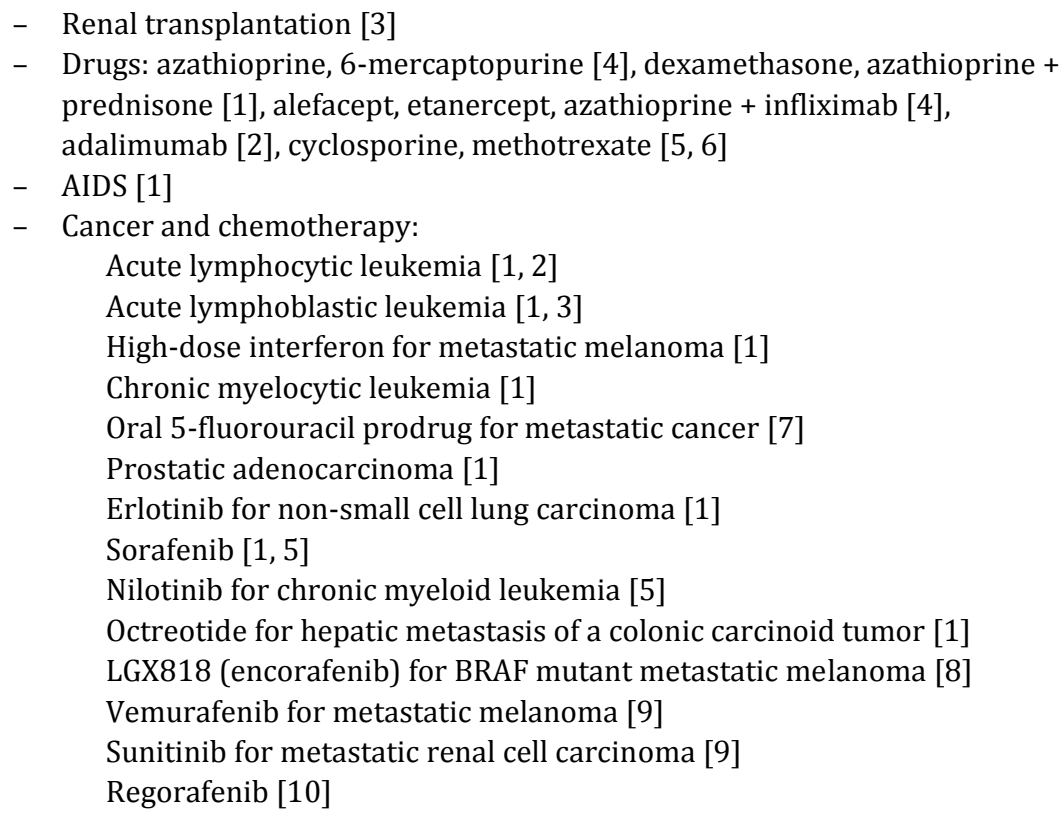 \\
\hline $\begin{array}{l}\text { Vesiculobullous } \\
\text { dermatoses }\end{array}$ & $\begin{array}{l}\text { Stevens-Johnson and Lyell syndromes }[1,2] \\
\text { Bullous epidermolysis }[1,2] \\
\text { Erythema multiforme }[1,2] \\
\text { Herpes zoster (the present case) }\end{array}$ \\
\hline Trauma & $\begin{array}{l}\text { Sunburn [4] } \\
\text { Sunbed [4] } \\
\text { Phototherapy (mini-PUVA) [11] } \\
\text { Head trauma [4] }\end{array}$ \\
\hline $\begin{array}{l}\text { Endocrine } \\
\text { causes }\end{array}$ & $\begin{array}{l}\text { Adrenocortical insufficiency [1] } \\
\alpha \text {-Melanocyte-stimulating hormone analogs [1] } \\
\text { Thyroid hormones [12] } \\
\text { Puberty, oral contraceptives, pregnancy [4] } \\
\text { Insulin [13] }\end{array}$ \\
\hline Miscellaneous & $\begin{array}{l}\text { Idiopathic or unknown }[1,4] \\
\text { Cutis marmorata telangiectatica congenita [4] } \\
\text { Nevus of Ota (+ sunbed exposure and oral contraceptives) [4] } \\
\text { Sulfur mustard gas [1] }\end{array}$ \\
\hline
\end{tabular}

